\title{
GIS tool to predict photosynthetically active radiation in a Dry Valley
}

\author{
DIMITRI ACOSTA (1), PETER T. DORAN (1) and MADELINE MYERS \\ Department of Geology and Geophysics, Louisiana State University, E235 Howe Russell Geosciences Complex, Baton Rouge, \\ LA 70803, USA \\ acosta.dimitri@epa.gov
}

\begin{abstract}
Understanding primary productivity is a core research area of the National Science Foundation's Long-Term Ecological Research Network. This study presents the development of the GIS-based Topographic Solar Photosynthetically Active Radiation (T-sPAR) toolbox for Taylor Valley. It maps surface photosynthetically active radiation using four meteorological stations with $\sim 20$ years of data. T-sPAR estimates were validated with ground-truth data collected at Taylor Valley's major lakes during the 2014-15 and 2015-16 field seasons. The average daily error ranges from $0.13 \mathrm{~mol}$ photons $\mathrm{m}^{-2}$ day $^{-1}(0.6 \%)$ at Lake Fryxell to $3.8 \mathrm{~mol}$ photons $\mathrm{m}^{-2}$ day $^{-1}(5.8 \%)$ at Lake Hoare. We attribute error to variability in terrain and sun position. Finally, a user interface was developed in order to estimate total daily surface photosynthetically active radiation for any location and date within the basin. T-sPAR improves upon existing toolboxes and models by allowing for the inclusion of a statistical treatment of light attenuation due to cloud cover. The T-sPAR toolbox could be used to inform biological sampling sites based on radiation distribution, which could collectively improve estimates of net primary productivity, in some cases by up to $25 \%$.
\end{abstract}

Received 2 December 2019, accepted 3 February 2020

Key words: ArcMap, automated weather station, digital elevation model, ice-covered lakes, McMurdo Dry Valleys, R model, Taylor Valley

\section{Introduction}

Solar radiation drives hydrological and biological systems. Visible light occupies a narrow waveband within short-wave radiation (SWR) between 400 and $700 \mathrm{~nm}$, and it is referred to as photosynthetically active radiation (PAR) because photoautotrophs harness this energy for primary production (McCree 1981). The total amount of PAR that reaches the Earth's surface is modulated by complex interactions with the atmosphere, which absorbs or scatters this energy. Understanding the spatial variability of incoming radiation that is available for photosynthesis is critical to developing accurate models for net primary productivity (NPP), surface hydrology and climatology (Mizoguchi et al. 2013).

Polar regions receive $24 \mathrm{~h}$ of sunlight during the summer and experience complete darkness during the winter, and annually receive significantly less solar energy than the equator. It is, however, equally important to note that on daily timescales, the greatest amount of solar radiation is received at the poles during the summer solstice. Less annual solar energy allows for cold temperatures (more freezing degree-days) and some lakes to maintain an ice cover through much of the summer. The McMurdo Dry Valleys (MDVs) of Antarctica are of particular interest because year-round liquid water in perennially ice-covered lakes provides an oasis for life in one of the harshest environments on the planet (Fountain et al.
1999). Current sampling of lake biology is restricted to a few locations per season due to lake ice cover and the availability of time and resources in the field. Present interpretations of these samples assume spatial homogeneity of biological processes across each lake (Hawes et al. 2014, Obryk et al. 2014).

The McMurdo Long-Term Ecological Research (MCM LTER) project maintains an array of automated weather stations (AWSs) distributed across various landscape units such as glacier surfaces, lakeshores and soil-sampling locations. Automated weather station-measured climate variables (soil and air temperatures, downwelling and upwelling radiation and wind speed, among others) span several decades (Doran et al. 2002).

Few studies have focused on implementing topographical spatial analysis in the MDVs in order to understand their broad environmental conditions. Dana et al. (1996) used SWR data, collected across Taylor, Wright and Victoria valleys, to develop a topographical radiation model (TRM) that mapped solar flux in the MDVs on monthly timescales. The TRM calculated global total radiation as the sum of direct, diffuse and reflected irradiance (Dubayah \& Rich 1995). Total surface SWR on the horizontal lake surfaces of the valley bottom was dependent on sky view factor (SVF; the percentage of the celestial dome that is unobstructed by local topography) (Dana et al. 1998). Modelled results show a north-to-south gradient of downwelling 
SWR. We improve upon the results presented in Dana et al. (1998) by increasing the spatial resolution and converting from SWR to PAR in order to improve estimates of NPP. This also allows for the incorporation of cloud cover (CC) for the extrapolation of measured radiation. This study utilizes a higher-resolution digital elevation model (DEM; $30 \mathrm{~m}$ ). The TRM used a $50 \mathrm{~km} \times 50 \mathrm{~km}$ DEM and digitized $30 \mathrm{~m}$ contour lines.

The Topographic Solar Photosynthetically Active Radiation (T-sPAR) toolbox is modified from existing ArcMap solar radiation toolboxes that were originally developed from Dubayah \& Rich (1995). It is a geographical information system (GIS)-based application of a physically based geometric solar radiation model (ESRI 2015). At each point, it accounts for upwardlooking viewshed, aspect, elevation and atmospheric conditions ( $\mathrm{Fu} \&$ Rich 2000). The T-sPAR toolbox improves upon current toolboxes by outputting PAR rather than SWR, which allows for better estimates of primary productivity. In addition, the toolbox allows for $\mathrm{CC}$ correction. The existing toolbox has been used in order to model radiation in the Quartermain Mountains of the MDVs (Lacelle et al. 2016). Lacelle et al. (2016) found that the toolbox systematically underestimated SWR, but correlated well with observations. We suggest that improvements could be made by increasing the input transmittivity from 0.6 to 0.7 , which we find is more appropriate for the MDVs.

\section{Study area: the MDVs}

Located on the western shore of the Ross Sea, the MDVs have an ice free area of $\sim 4500 \mathrm{~km}^{2}$, making them the single largest area that is free of ice and snow in Antarctica (Fig. 1) (Levy 2013). Local topography is typical of glacially carved valleys. Elevation ranges from a few metres above sea level along the valley floors to over $3000 \mathrm{~m}$ for the peaks. The summer months of December, January and February receive continuous sunlight equivalent to levels received along the equator (Dhaulakhandi et al. 1993). Valley bottom mean annual air temperatures range from $-22^{\circ} \mathrm{C}$ to $-18^{\circ} \mathrm{C}$ (Doran

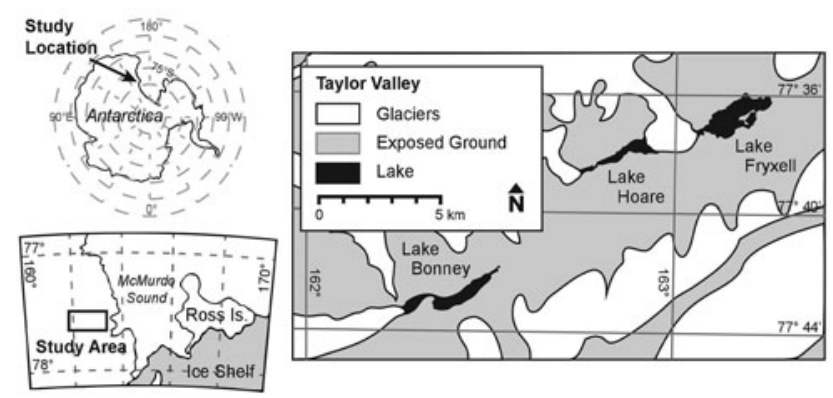

Fig. 1. Location of the MDVs and the area of study. et al. 2002). The lower albedo of the rocky surface causes warmer summer temperatures in the MDVs compared to nearby areas covered in ice (Chinn 1993). Surface soil temperatures have been observed to reach $\sim 10^{\circ} \mathrm{C}$ along the valley floor throughout the MDVs (Doran et al. 2008). Annual totals for snowfall range between 3 and $50 \mathrm{~mm}$ of water equivalent (Fountain et al. 2010) and are less than the evaporation potential in the area, making it a cold desert (Bromley 1986).

\section{Methods}

The T-sPAR model was developed using three primary data sources: 1) long-term meteorological data, 2) field surveys of surface PAR and 3) a $30 \mathrm{~m}$ DEM. Long-term AWS data are used to derive the conversion factor from SWR to PAR. Statistical analysis of AWS radiation measurements was used in order to estimate maximum potential PAR at each location. Maximum potential PAR was compared with recorded PAR in order to develop a model for estimating CC. Point ground-truth measurements taken during the 2014-15 and 2015-16 field seasons were used to quantify the contribution of the skylight fraction to the global total and to evaluate the model sensitivity to rapid topographical shading. The $30 \mathrm{~m}$ DEM was the primary T-sPAR input for estimating maximum potential surface PAR under 'cloudless' conditions. Outputs were then validated against measured PAR, correcting for $\mathrm{CC}$ using inverse distance weighting (IDW) (Csatho et al. 2005).

\section{Meteorological record}

The PAR data were collected between 1996 and 2015, sampled every $30 \mathrm{~s}$ and recorded as $15 \mathrm{~min}$ averages from four weather stations in Taylor Valley: Lake Bonney (BOYM), Explorer's Cove (EXEM, records span 1997-2015), Lake Fryxell (FRLM) and Lake Hoare (HOEM). The stations record PAR as instantaneous values given in $\mu \mathrm{mol}$ photon $\mathrm{m}^{-2} \mathrm{~s}^{-1}$. The PAR was measured using LI-COR model LI-190 Quantum Sensors. The stations simultaneously measure SWR using either Eppley PSP or LI-COR LI-200 pyranometers. Data are recorded and stored by Campbell Scientific CR10x data loggers and are accessible from the MCM LTER website (http://mcm.lternet.edu).

Anomalous data are removed by comparing values from the same calendar day and separated into years defined from 22 June to 21 June of the following year, coincident with the winter solstice. First light is observed in the valley on 9 August based on PAR flux $\geq 1 \mu \mathrm{mol}$ photon $\mathrm{m}^{-2} \mathrm{~s}^{-1}$ for a minimum of $1 \mathrm{~h}$ over $24 \mathrm{~h}$. Last light is observed on 4 May by the same criterion. Values 
between last and first light were set to zero. Daily flux is derived from integrating $15 \mathrm{~min}$ averages of flux rate.

We derive a locally estimated scatterplot smoothing (LOESS) curve for each station from daily observed minimum, mean and maximum fluxes at each station. The fit at $x$ is made from nearby points as a function of the distance from $x$ (Cleveland \& Devlin 1988). A smoothing parameter $\alpha$ controls the number of data points included in the estimate $(\alpha>1$ produces smoother fits while $\alpha<1$ conforms more closely to the data) (Cleveland \& Devlin 1988). The LOESS curves represent the smoothed average of the daily observations over the whole record. They are interpreted as the potential maximum daily PAR under 'cloudless' conditions and are used in order to validate T-sPAR estimates.

Daily changes in CC are approximated by the change in atmospheric transmittivity over time. High transmittivity is positively correlated with PAR and SWR and negatively correlated with CC. The LOESS best fit curve for maximum total daily PAR is assumed to be equal to $0 \%$ CC. Deviation below the maximum total daily PAR is attributed to increased CC. Daily CC was calculated as a percentage using Eq. (1):

$$
\begin{aligned}
& \mathrm{CC}=\left[1-\left(\frac{\text { Measured total daily } P A R}{\text { Estimated total daily PAR }}\right)\right] \times k \\
& \mathrm{CC}>1=1 \text { and } \mathrm{CC}<0=0
\end{aligned}
$$

where $k$ is a constant fit to the data and used to constrain $\mathrm{CC}$ values between 0 and 1 . A value of 1 equates to overcast conditions persisting for all or most of the day, while a value of 0 indicates sustained clear conditions. Intermediate values indicate scattered $\mathrm{CC}$ throughout the day or high $\mathrm{CC}$ during peak radiation hours transitioning to clear conditions during off-peak hours. Estimation of daily $\mathrm{CC}$ relies on the sum of daily measured PAR. Only records with all daily observations were included in this analysis. Records with fewer daily observations would be biased towards lower sums and inaccurately identified as days of high CC. Values outside of the CC limits of $0-1$ are possible, as the optical thickness of cloud coverage can still vary within completely overcast days. Conversely, diffuse radiation concentration under scattered cloud conditions can result in measured values that exceed the estimated total daily value (Orgill \& Hollands 1977). For this analysis, values $<0$ were set to 0 , and values $>1$ were set to 1 .

Seven overcast days were examined in order to identify the effect of heavy CC on total daily PAR and to establish a $k$ value. These dates had confirmed snow events or overcast conditions over a $24 \mathrm{~h}$ period. Incoming and outgoing SWR values were cross-referenced in order to confirm that the decrease in daily values was not caused by snow obstructing the sensor. The $k$ value is derived from Eq. (1) based on observed $100 \% \mathrm{CC}$ and the fraction of measured PAR out of the LOESS-derived maximum potential PAR.

\section{Field surveys}

We utilize diurnal topographical shading in order to measure the skylight contribution to global total radiation so as to evaluate T-sPAR parameters as well as to assess the spatial and temporal accuracy of the toolbox over small spatial and time scales. The skylight contribution was measured at HOEM and FRLM. The PAR flux at HOEM is typically less than at FRLM due to the reduced sky view. We scale the PAR flux recorded at the stations to match between 30 December 2013 and 6 January 2014 in order to approximate the background radiation with no topographical shading.

Ground-truth measurements of surface PAR in Taylor Valley were recorded between October and December of the 2015-16 field season using Onset HOBO pendant light sensors and LI-190 Quantum Sensors. HOBO light sensors are not cosine-corrected, so first we tested their accuracy in order to determine whether they could be used in other field surveys. Toolbox accuracy was determined from a field survey at Lake Hoare (LH), which experiences the most extreme topographical shading.

The period between 30 December 2013 and 6 January 2014 was examined in order to evaluate the contribution of diffuse and reflected radiation to global radiation. These dates were chosen based on cloudless conditions and equivalent daily maximum PAR at both HOEM and FRLM. During this time of year, local topography shadows HOEM between $16 \mathrm{~h} 00$ and 16h30, while FRLM remains in direct sunlight. Measured values at FRLM represent global total surface radiation, while HOEM lacks the incident fraction due to topographical obstruction.

The experiment to evaluate HOBO sensor accuracy was set up at Lake Bonney (LB). The goal was to verify that under equal conditions all sensors measured flux in a reliable and predictable way. All sensors were set up with the same aspect, next to each other on a north-facing slope. A LI-COR LI-190 Quantum Sensor was placed in the centre, with five HOBO sensors on each side, and they were set to record for a period of 1 week. The magnitude recorded by the HOBO sensors was inaccurate, but the HOBO sensors reliably provided a qualitative measure of increasing or decreasing radiation. Long et al. (2012) simultaneously collected 15 min data from both HOBO pendants and LI-COR Quantum Sensors in both laboratory and field settings. They found no lag in the timing of the sensor response and only minor disagreement in the magnitude at $\sim 27^{\circ} \mathrm{N}$ and $42^{\circ} \mathrm{N}$. We therefore used the HOBO sensors 
in order to assess the toolbox's accuracy in predicting the timing of topographical shading at various locations.

Ten Onset HOBO pendant light sensors were deployed across Taylor Valley's three major lakes for a period of 1 week. Data were also simultaneously collected with the Quantum Sensor and LI-1400 data logger. The Quantum Sensor and a HOBO sensor were set beside the local AWS for the duration of the sample period as reference controls. HOBO sensors measured every $15 \mathrm{~min}$, while the LI-1400 data logger sampled every $5 \mathrm{~min}$ and logged the mean every $15 \mathrm{~min}$ (this routine was tested and found to be in close agreement with meteorological data). Sample locations for the HOBO sensors were chosen in order to maximize the network's spatial distribution. Measurements were taken on the lake's surface and lakeshore at points with unique topographical characteristics such as diurnal topographical shading, free of shade when other locations are shaded or of uncommon surface ablation. EXEM was included as a reference station due to its isolation from any major ice-covered lakes or glaciers in order to minimize the effect of highly reflective surfaces. Located $\sim 5 \mathrm{~km}$ east-north-east of Lake Fryxell (LF) and $\sim 3 \mathrm{~km}$ west of McMurdo Sound, EXEM occupies one of the widest points in Taylor Valley and receives the least amount of topographical shading.

An additional topographical shading experiment was conducted on 11 December 2014 on a clear sunny day along a transect that transitioned from full sunlight into shade on the north-east shore of LH. At this time of year, the basin becomes shaded between $18 \mathrm{~h} 50$ and 20 h00 by the Asgard Range to the north-west. Flux measurements were taken using the Quantum Sensor, beginning under full incident radiation and transitioning to shade. Measurements were taken perpendicular to the umbral horizon (boundary of the topographical shadow) in order to evaluate the accuracy of T-sPAR over smaller spatial and time scales. Measurements were also taken in the shade of large boulders under incident and shaded conditions in order to evaluate the effect of limited sky view area.

\section{T-sPAR toolbox development}

Area and Point T-sPAR toolboxes were developed from pre-existing ArcMap Solar Radiation toolboxes and optimized for Taylor Valley. Atmospheric transmittivity and diffusivity have been modified to reflect the increased atmospheric transmittivity in Antarctica. The DEM is built into the toolbox. The only information that needs to be supplied by the user is a time configuration, CC values and, in the case of Point T-sPAR, the location where PAR is to be calculated.

The $30 \mathrm{~m}$ DEM in this study uses the Projected Coordinate System WGS 1984 Lambert Conformal Conic and has an elevation range of $0-3199 \mathrm{~m}$ and a total area of $10017 \mathrm{~km}^{2}$ (Csatho et al. 2005). The DEM and shapefiles for AWS locations and lake outlines are available from the MCM LTER data repository (http://mcm.lternet.edu/ power-search/data-set). Files were processed using ArcGIS v10.3.0.4322 with Spatial Analyst. An area of interest of $673 \mathrm{~km}^{2}$ was created from the DEM using the basin limits model (http://mcm.lternet.edu/power-search/data-set). Lake surface area was updated using a Landsat 8 image taken on 19 December 2014 (https://libra.developmentseed.org, LC80561162014353LGN00, accessed 1 January 2015). Updated shapefiles had a new surface area of $6.820 \mathrm{~km}^{2}$ for LF, $2.270 \mathrm{~km}^{2}$ for $\mathrm{LH}$ (which now includes Lake Chad) and $4.533 \mathrm{~km}^{2}$ for LB.

First, T-sPAR outputs were calculated using ArcMap's Point Solar Radiation tool (Point T-sPAR) and the Area Solar Radiation tool (Area T-sPAR). Estimates were limited between 20 August and 23 April due to the software's limitations in modelling surface radiation correctly at angles $<10^{\circ}$ above the horizon (ESRI 2015). Low solar angles cause diffuse radiation to contribute a greater fraction of global radiation at the expense of decreased transmittivity. We minimized differences in input computational parameters when comparing Point T-sPAR and Area T-sPAR estimates (Table I). A 'sky size/resolution' of 4000 was necessary for Point T-sPAR to resolve overlapping sun maps for periods with a high temporal resolution $(<24 \mathrm{~h})$, and solstices were computed using the 'special day' time configuration (ESRI 2015).

Atmospheric transmittivity and diffuse components were optimized for Taylor Valley by comparing LOESS

Table I. T-sPAR computation parameters used to estimate surface PAR by point and area for the Taylor Valley basin.

\begin{tabular}{|c|c|c|}
\hline Parameters & Point T-sPAR & Area T-sPAR \\
\hline Input raster & TV Basin AOI & TV Basin AOI \\
\hline $\begin{array}{l}\text { Input point feature } \\
\text { or table }\end{array}$ & $\begin{array}{l}\text { Meteorological and } \\
\text { ground-truth locations }\end{array}$ & NA \\
\hline Height offset & 0 & 0 \\
\hline Latitude & -77.642 & -77.642 \\
\hline Sky size/resolution & 4000 & 200 \\
\hline Time configuration & Within a day & $\begin{array}{c}\text { Multiple days in a } \\
\text { year }\end{array}$ \\
\hline Start day & 8/20 (JD 232) & 8/20 (JD 232) \\
\hline End day & 4/23 (JD 113) & 4/23 (JD 113) \\
\hline Day interval & NA & 14 \\
\hline Hour interval & 0.25 & NA \\
\hline $\begin{array}{l}\text { Create outputs for } \\
\text { each interval }\end{array}$ & Yes & Yes \\
\hline Zenith divisions & 24 & 24 \\
\hline Azimuth divisions & 24 & 24 \\
\hline Diffuse model type & UNIFORM_SKY & UNIFORM_SKY \\
\hline Diffuse proportion & Varied $0.2-0.4$ & Varied $0.2-0.4$ \\
\hline Transmittivity & Varied $0.6-0.9$ & Varied $0.6-0.9$ \\
\hline
\end{tabular}

$\mathrm{AOI}=$ area of interest, $\mathrm{JD}=$ Julian day, $\mathrm{TV}=$ Taylor Valley. 
curves with T-sPAR outputs in order to identify the Point T-sPAR parameters that predicted actual observations with the greatest fidelity. The diffuse component (D) was varied between 0.2 and 0.4 based on the measured diffuse fraction $(1.0=100 \%$ of global radiation). Transmittivity $(\mathrm{T})$ was varied between 0.5 and 0.9 . Adjustments of atmospheric values change surface estimates by orders of magnitude. Outputs are converted from SWR to PAR using a conversion factor of $0.383 \mathrm{~W} \mathrm{~m}^{-2}$ per $1 \mu \mathrm{mol}$ photon $\mathrm{m}^{-2} \mathrm{~s}^{-1}$ based on the average PAR fraction recorded across all stations from October through March of the entire record. The root mean square deviance (RMSD) between LOESS values and Point T-sPAR outputs was calculated for each iteration. The parameters that generated the smallest RMSD values were used to calculate Area T-sPAR over 2 week periods.

\section{Results}

\section{Estimating cloud-free surface PAR}

A LOESS curve with a value of $\mu+1 \sigma$ for maximum daily flux observations was chosen to represent the absolute potential maximum daily flux. This value includes $84 \%$ of daily maximum observations over the entire record (Fig. 2). A value of $\alpha=0.25$ generated curves that best described the maximum daily flux for all calendar days. The optimized parameters accurately predict PAR flux values of $>\sim 1600 \mu \mathrm{mol}$ photons $\mathrm{m}^{-2} \mathrm{~s}^{-1}$ during the summer solstice of the 2014-15 field season; however, these values are up to $\sim 250 \mu \mathrm{mol}$ photons $\mathrm{m}^{-2} \mathrm{~s}^{-1}$ higher than best-fit mean LOESS curve values for all years included in this study. Larger LOESS $\sigma$ and $\alpha$ values overestimated daily maximums at the beginning and

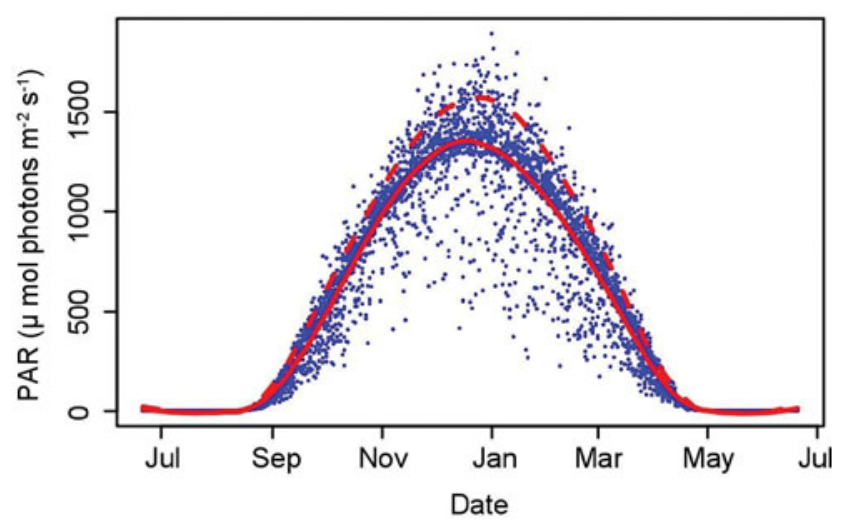

- Observations - Mean Loess -- Confidence Interval

Fig. 2. Mean LOESS best-fit curve for daily maximums observed at EXEM. One standard deviation above the best-fit curve includes $84 \%$ of all observations. This confidence interval curve was chosen in order to represent the absolute maximum potential surface PAR for that station. end the season, but better predicted PAR flux near ( \pm 14 days) the summer solstice.

Surface PAR flux is comparable for all stations during the peak of the summer (Table II). BOYM has the largest range in expected daily values (1262 $\mu \mathrm{mol}$ photons $\mathrm{m}^{-2} \mathrm{~s}^{-1}$ ) and receives the lowest total daily PAR $\left(65.34 \mathrm{~mol}\right.$ photons $\mathrm{m}^{2}$ ), although only $7.39 \mathrm{~mol}$ photons $\mathrm{m}^{2}$ less than EXEM, which receives the highest total daily PAR. The envelopes for FRLM and EXEM are most similar to each other (1194 and $1157 \mu \mathrm{mol}$ photons $\mathrm{m}^{-2} \mathrm{~s}^{-1}$ ), and both receive intermediate amounts of surface PAR over the course of the season compared to other stations. HOEM absolute maximum, mean maximum and mean average surface PAR values are the lowest with respect to all other AWS included in this study (Table II), which is consistent with heavy daily topographical shading in the narrow valley. Daily maximum surface PAR flux values of $500 \mu \mathrm{mol}$ photons $\mathrm{m}^{-2} \mathrm{~s}^{-1}$ are recorded at all stations by October, and they double to $1000 \mu \mathrm{mol}$ photons $\mathrm{m}^{-2} \mathrm{~s}^{-1}$ by November. Values $>1500 \mu \mathrm{mol}$ photons $\mathrm{m}^{-2} \mathrm{~s}^{-1}$ are observed from late November through mid-January. Daily values drop to $<1000 \mu \mathrm{mol}$ photons $\mathrm{m}^{-2} \mathrm{~s}^{-1}$ by late February and to $<500 \mu \mathrm{mol}$ photons $\mathrm{m}^{-2} \mathrm{~s}^{-1}$ by mid-March.

\section{Modelled CC in the MDVS}

The PAR flux vales recorded by the AWS were compared to the expected daily values based on the LOESS curve (Table III). Observed overcast days suggest that a 50\% decrease in daily PAR flux equals $100 \%$ CC. One exception highlights the inefficiency of this method in capturing brief cloudy periods during low background radiation. On 23 October 2015, it began to snow in the evening after peak radiation hours. Close examination of the FRLM record shows little difference compared to a cloud-free day. The only signal that is appreciable in the record is lower than expected values during the 'night-time' hours, when solar angles are lowest and PAR values are inherently low. This event highlights the

Table II. Expected total daily and total seasonal PAR flux for the summer solstice calculated from data averages recorded between 1996 and 2015 by meteorological location.

\begin{tabular}{lrrrr}
\hline $\begin{array}{l}\text { Daily PAR flux } \\
\left(\mu \text { mol photons } \mathrm{m}^{-2} \mathrm{~s}^{-1}\right)\end{array}$ & BOYM & EXEM & FRLM & HOEM \\
\hline Absolute maximum & 1622 & 1571 & 1598 & 1540 \\
Mean maximum & 1375 & 1354 & 1348 & 1277 \\
Mean Average & 636 & 700 & 680 & 627 \\
Mean minimum & 113 & 197 & 154 & 171 \\
$\begin{array}{l}\text { Total daily PAR } \\
\left(\text { mol photons m }{ }^{-2} \text { ) }\right.\end{array}$ & 65.34 & 72.73 & 71.83 & 67.23 \\
$\begin{array}{l}\text { Total annual PAR } \\
\left(\text { mol photons } \mathrm{m}^{-2}\right)\end{array}$ & 7584 & 8477 & 8479 & 6938 \\
\hline
\end{tabular}


Table III. Measured total daily PAR ( $\mathrm{mol}$ photons $\mathrm{m}^{-2}$ ) versus expected total daily PAR for days with heavy CC and snow.

\begin{tabular}{lccccc}
\hline Date & $\begin{array}{c}\text { Location } \\
\text { observed }\end{array}$ & $\begin{array}{c}\text { Snow } \\
\text { event }\end{array}$ & $\begin{array}{c}\text { Measured } \\
\text { daily PAR }\end{array}$ & $\begin{array}{c}\text { Expected } \\
\text { daily PAR }\end{array}$ & $\begin{array}{l}\text { Percentage } \\
\text { of total }\end{array}$ \\
\hline 18 Nov 2014 & LB & No & 23.83 & 53.93 & 44 \\
27 Nov 2014 & LB & Yes & 28.59 & 59.19 & 48 \\
30 Nov 2014 & LB & No & 33.98 & 60.65 & 56 \\
23 Oct 2015 & LF & Yes & 29.91 & 35.18 & 85 \\
31 Oct 2015 & LF & Yes & 17.81 & 43.23 & 41 \\
6 Dec 2015 & LF & No & 41.08 & 69.29 & 59 \\
8 Dec 2015 & LF & No & 35.39 & 69.99 & 51 \\
\hline
\end{tabular}

difficulty in identifying cloud coverage when solar elevation is low.

Cloud cover values were used to bin overcast conditions into four categories: clear $(0$ to $<0.2)$, scattered $(0.2$ to $<0.5)$, broken $(0.5$ to $<0.8)$ and overcast $(0.8$ to $<1.0)$. Frequency statistics were calculated for each year along with a seasonal total by meteorological station (Table IV). Monthly totals show that cloudiness is typically greatest at EXEM meteorological station, at the eastern end of Taylor Valley. This location has the highest incidence of both overcast and broken cloud conditions, accounting for up to $32 \%$ of all observations during a season. Clear conditions, on the other hand, are most common at the western end of Taylor Valley near BOYM meteorological station.

The frequency of modelled observations was aggregated by month in order to determine whether atmospheric patterns concentrate at specific times during the summer (Fig. 3). The results show that cloud-free, clear days predominate across Taylor Valley for most of the summer, with a slight decrease in frequency as the summer progresses. The change in frequency appears well correlated between observations at BOYM, EXEM and FRLM meteorological stations, with all three stations reaching a peak during the month of February. HOEM is the only station that shows a distinct increase in overcast conditions around the summer solstice.

\section{Measured diffusivity}

The PAR flux measured at FRLM and HOEM between 30 December 2013 and 6 January 2014 was analysed in order to estimate the contribution of skylight radiation at HOEM (Fig. 4). Scaling FRLM for this interval to match

Table IV. Summary statistics for seasonal cloud coverage near meteorological station based on PAR data.

\begin{tabular}{lcccc}
\hline Meteorological location & Clear & Scattered & Broken & Overcast \\
\hline EXEM & $44 \%$ & $23 \%$ & $17 \%$ & $15 \%$ \\
FRLM & $46 \%$ & $25 \%$ & $15 \%$ & $14 \%$ \\
HOEM & $47 \%$ & $26 \%$ & $17 \%$ & $10 \%$ \\
BOYM & $53 \%$ & $28 \%$ & $12 \%$ & $7 \%$ \\
\hline
\end{tabular}

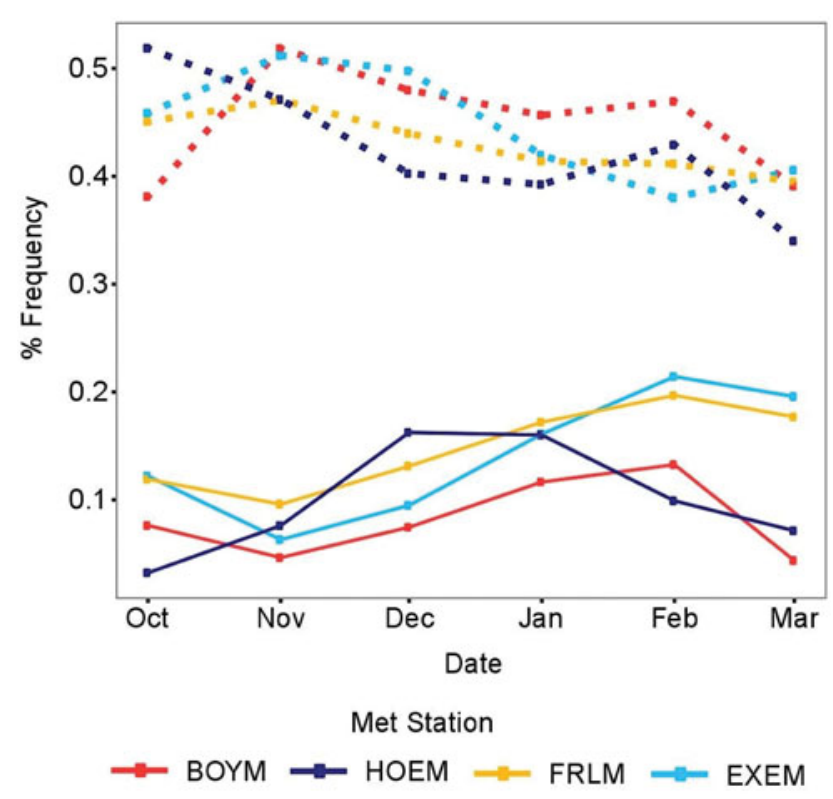

Fig. 3. Frequency of daily $\mathrm{CC}$ by meteorological station. Total observations are aggregated by month and displayed as a percentage of the monthly total. Only 'clear' (dashed lines) and 'overcast' (solid lines) conditions are shown in order to improve readability.

HOEM yields a predicted mean PAR flux at FRLM of $\sim 941 \mu \mathrm{mol}$ photons $\mathrm{m}^{-2} \mathrm{~s}^{-1}$, while the average flux in full topographical shade is $\sim 247 \mu \mathrm{mol}$ photons $\mathrm{m}^{-2} \mathrm{~s}^{-1}$. The PAR flux under shade conditions relative to full sun conditions represents an incident fraction of $74 \%$ and a skylight fraction of $26 \%$ for FRLM. The fraction of incident light at FRLM is greater than at HOEM. At HOEM, the mean unshaded value was $~ 946 \mu \mathrm{mol}$ photons $\mathrm{m}^{-2} \mathrm{~s}^{-1}$ versus the mean shaded value of $\sim 144 \mu \mathrm{mol}$ photons $\mathrm{m}^{-2} \mathrm{~s}^{-1}$, which represents an incident contribution of $85 \%$ and a skylight contribution of $15 \%$ to the total global value.

\section{T-sPAR toolbox development}

First, Point T-sPAR parameters of diffusivity (D) and transmittivity $(\mathrm{T})$ were tested in order to optimize the fit to LOESS curves for all four AWS. Optimal diffusivity and transmittivity were chosen based on lowest RMSD. Higher transmittivity and diffusivity inherently increase PAR estimates. ArcMap default parameters of $D=0.3$ and $\mathrm{T}=0.5$ predict total annual surface PAR to be highest at BOYM. Across all stations in Taylor Valley, $\mathrm{D}=0.3$ and $\mathrm{T}=0.7$ yielded the minimal average daily error of $0.5 \mathrm{~mol}$ photons $\mathrm{m}^{-2}$ or $\sim 2.5 \%$ of the average daily PAR at any one station (Fig. 5). During the solstice, these parameters predict higher PAR at BOYM than FRLM by $\sim 4$ mol photons $\mathrm{m}^{-2}$ day $^{-1}$, but increasing the transmittivity reduces the error surrounding the solstice 


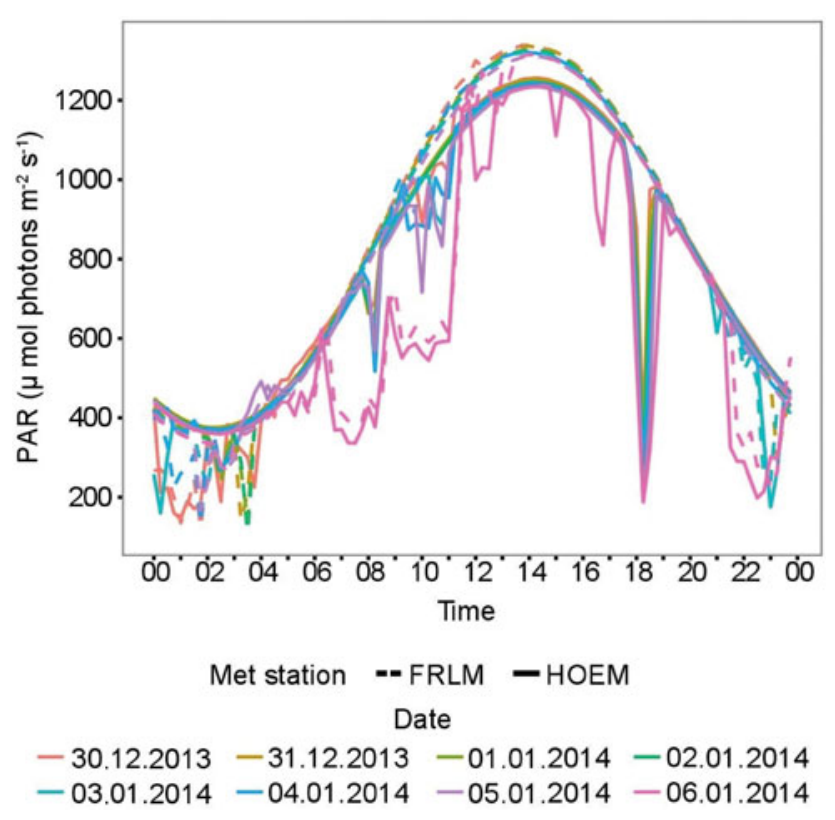

Fig. 4. PAR measured at FRLM and HOEM between

30 December 2013 and 6 January 2014. At this time of year, HOEM is shaded daily at approximately $18 \mathrm{~h} 00$ by local topography. The plot shows that the diffuse component of PAR measured at HOEM at $18 \mathrm{~h} 15$ is $~ 26 \%$ of the value measured at FRLM.

by $\sim 15 \mathrm{~mol}$ photons $\mathrm{m}^{-2}$ day $^{-1}$. Transmittivity values of $>0.7$ for $0.2<\mathrm{D}<0.4$ result in the toolbox overestimating incident radiation by $16-55 \mathrm{~mol}$ photons $\mathrm{m}^{-2}$ day $^{-1}$ during peak radiation. Transmittivity values of $<0.7$ under the same diffusivity conditions result in an underestimation of incident radiation by $5-27 \mathrm{~mol}$ photons $\mathrm{m}^{-2}$ day $^{-1}$. Transmittivity varies on larger spatial scales than diffusivity, and this is evident in the optimum parameter for each AWS. While $\mathrm{T}=0.7$ produces the

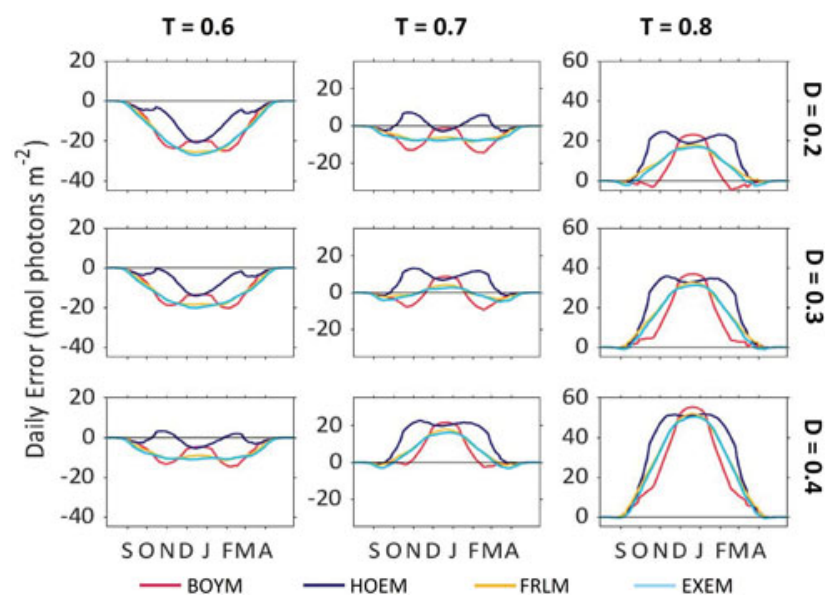

Fig. 5. Daily T-sPAR error estimated from LOESS best-fit curves for each station at various diffusivity and transmittivity values, indicated in the top and right margins. least error for all stations, the optimum diffusivity varies at the basin scale.

For $\mathrm{T}=0.7$, a value of $\mathrm{D}=0.3$ minimizes the mean error at both FRLM and EXEM $(0.2$ and $0.7 \mathrm{~mol}$ photons $\mathrm{m}^{-2} \mathrm{day}^{-1}$, respectively), which, due to their proximity and location in the same basin, have a similar, larger SVF than HOEM and BOYM, which are in the narrower portion of Taylor Valley. During the spring and autumn, T-sPAR under-predicts PAR by $\sim 2 \mathrm{~mol}$ photons $\mathrm{m}^{-2} \mathrm{day}^{-1}$ on average. From November through February, the error gradually ramps up from 0 to only $4 \mathrm{~mol}$ photons $\mathrm{m}^{-2} \mathrm{day}^{-1}$. During this time, PAR is over-predicted at HOEM by $12 \mathrm{~mol}$ photons $\mathrm{m}^{-2}$ day $^{-1}$. It is under-predicted at BOYM by $7.5 \mathrm{~mol}$ photons $\mathrm{m}^{-2}$ day $^{-1}$ on average ( $25 \%$ cumulative error). FRLM and EXEM are only under-predicted by $2.5 \mathrm{~mol}$ photons $\mathrm{m}^{-2}$ day $^{-1}$ (6.8\% cumulative error). At BOYM, we see a variability in the toolbox accuracy with sun elevation, although the magnitude of the error is approximately double that of HOEM and FRLM. A value of $0.2<\mathrm{D}<0.3$ would probably reduce the error at BOYM. Reducing the diffuse component from 0.3 to 0.2 reduces the toolbox error at HOEM from 3.8 to $0.6 \mathrm{~mol}$ photons $\mathrm{m}^{-2}$ day $^{-1}$. Lower diffusivity values are also in closer agreement with field observations.

We attribute the error in September and April to the toolbox inaccuracy at predicting radiation when solar angles are low due to the increased sensitivity to small fluctuations in atmospheric conditions owing to the increased ray path. There is also a larger PAR fraction of SWR, and the conversion factor from SWR to PAR is probably higher both before October and after March.

\section{Testing T-sPAR outputs}

The toolbox predicts the highest annual surface PAR at EXEM ( $8490 \mathrm{~mol}$ photons $\mathrm{m}^{-2}$ ) and lowest annual surface PAR at HOEM $\left(7375 \mathrm{~mol}\right.$ photons $\left.\mathrm{m}^{-2}\right)$. A period of three consecutive days with clear atmospheric conditions was chosen from each basin sample run in order to compare daily AWS, Quantum Sensor and HOBO pendant measurements, corresponding to 25-27 October 2015 for the LF, 9-11 November 2015 for the LH and 27-29 November 2015 for LB. Daily AWS and Quantum Sensor measurements for these intervals had similar diurnal envelopes of $\sim 18 \mathrm{~h}$ depending on location and consistent daily maximums and minimums. Modelled results plotted against observed values match closely $( \pm 50 \mu \mathrm{mol}$ photons $\left.\mathrm{m}^{-2} \mathrm{~s}^{-1}\right)$, predicting large topographical shading events as evidenced by data collected in the LH basin (Fig. 6).

During the HOBO sensor calibration field experiment, sensors accurately responded to increasing or decreasing surface PAR, but the magnitude of their response was unpredictable. T-sPAR mostly under-predicted PAR, sometimes by as much as $750 \mu \mathrm{mol}$ photons $\mathrm{m}^{-2} \mathrm{~s}^{-1}$. 


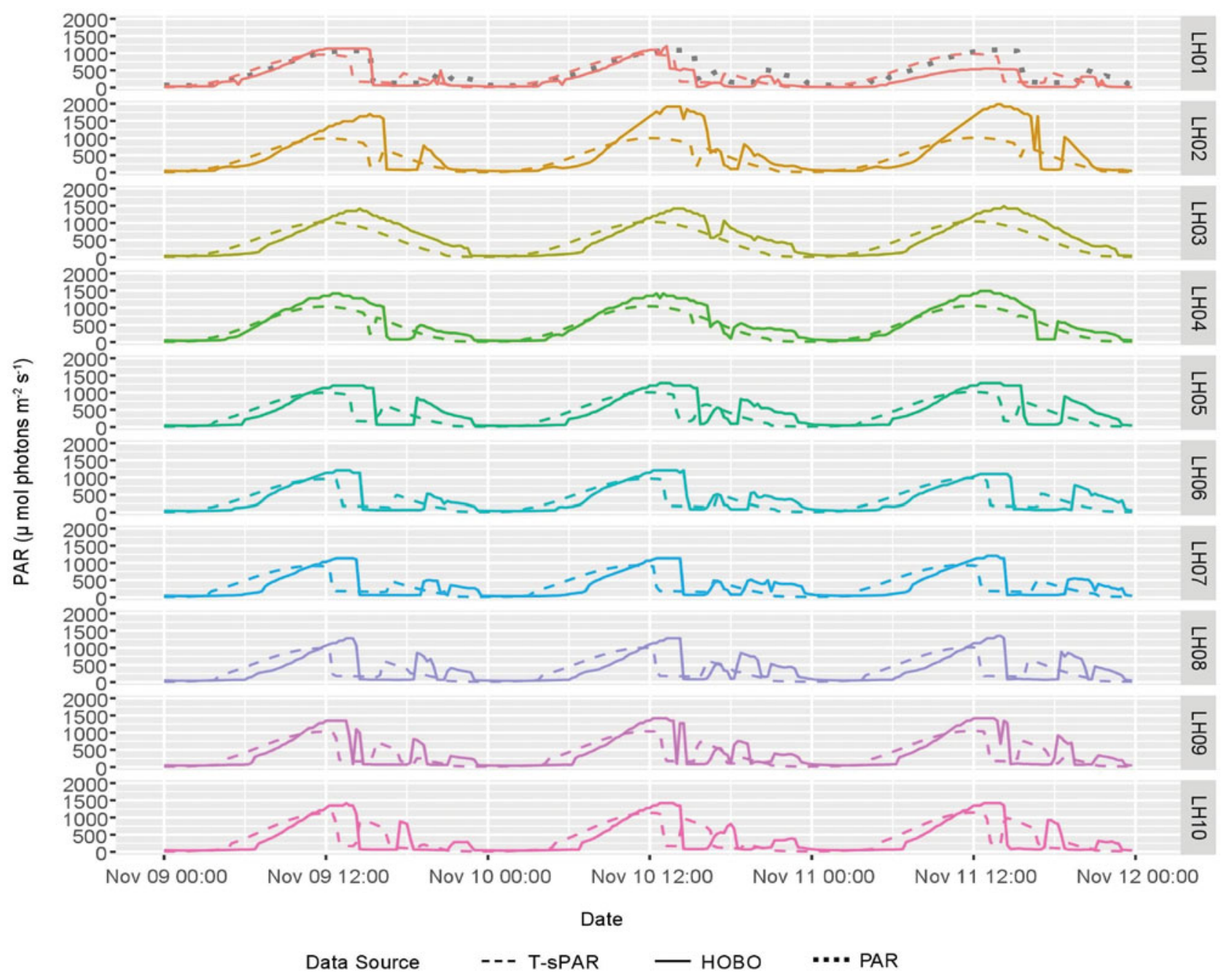

Fig. 6. Surface PAR measured with HOBO sensors plotted against Point T-sPAR estimates.

T-sPAR predictions rarely exceeded AWS measurements by $\sim 100 \mu \mathrm{mol}$ photons $\mathrm{m}^{-2} \mathrm{~s}^{-1}$ on average. A comparison of T-sPAR modelled sensor locations versus recorded observations shows a shallowing of the trough created

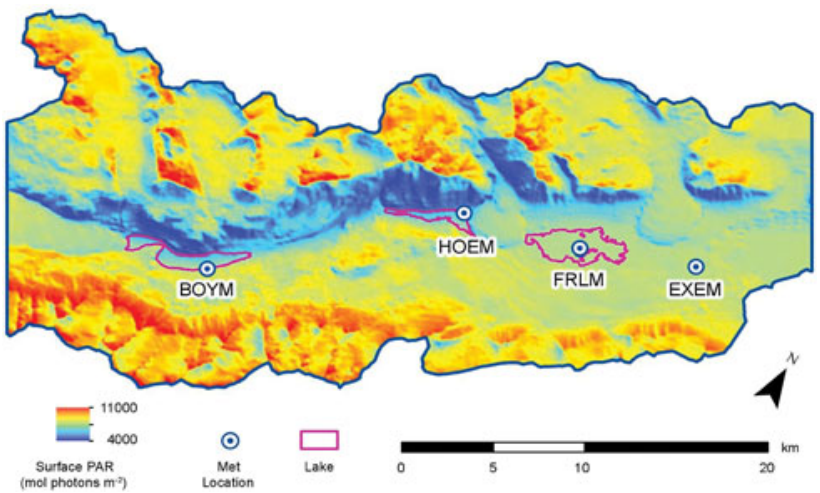

Fig. 7. Total annual surface PAR for the Taylor Valley basin estimated using the Area T-sPAR. by topographical shading by $\sim 10 \mu \mathrm{mol}$ photons $\mathrm{m}^{-2} \mathrm{~s}^{-1}$ over 2 days as the solar elevation increases from day to day (Fig. 6). The cause of the difference between estimated and observed values is their temporal synchronization. The model responds to shadowing before the actual observation by $\sim 3 \mathrm{~h}$. This is an artefact of the spatial resolution of the DEM combined with the sky view resolution and ArcMap's sun position algorithm. At a resolution of $30 \mathrm{~m}$, shadows will be estimated to be present over areas both before and after they are physically present. A small error in the sun position algorithm will predict a location that is off by a few degrees, which will have an impact on modelled ray tracing within the DEM. A coarse resolution for the sky view will affect the sun position and subsequent ray tracing.

Although the magnitude of T-sPAR outputs cannot be validated from the HOBO surveys, HOBO measurements helped evaluate T-sPAR's ability to predict the timing of shading accurate to within a few 
hours (Fig. 6). When the magnitudes of hourly T-sPAR outputs are compared to hourly AWS data at HOEM (Fig. 6a), this reveals the accuracy in the magnitude of PAR flux at HOEM under extreme topographical shading.

\section{Spatial and temporal variability in surface PAR}

Once model parameters were validated, surface PAR for Taylor Valley for the summer was estimated from Area T-sPAR (Fig. 7). Areas of high elevation and north-facing slopes receive the greatest amounts of surface PAR, while south-facing slopes received the least total radiation. Annual values of $>10000 \mathrm{~mol}$ photons $\mathrm{m}^{-2}$ are only found at the highest points along the ridgeline, where a high SVF allows for unobstructed incident radiation throughout the entire day and at the lowest solar angles. The south-facing slopes of the Asgard Range receive annual values of between 4000 and 6000 mol photons $\mathrm{m}^{-2}$. The western end of the LB and LH basins receive the most PAR. The north-facing slopes of the Kukri Hills generally receive annual values of $8000-10 \quad 000 \mathrm{~mol}$ photons $\mathrm{m}^{-2}$, and values increase from east to west. The annual PAR values on the valley floor range between 6000 and $8000 \mathrm{~mol}_{\text {photons }} \mathrm{m}^{-2}$, with the lowest parts of the valley receiving less PAR than higher ground.

Total daily surface radiation appears to decline from east to west, suggesting a correlation with total width of the valley floor and height of the surrounding ridgeline. The largest daily totals were observed at EXEM at the height of summer, followed closely by FRLM, with comparable total daily values and only slightly higher totals for the entire season (Table II). Estimates for BOYM data show higher total seasonal values compared to HOEM. The PAR values at HOEM exceed BOYM by $2 \mathrm{~mol}$ photons $\mathrm{m}^{-2}$ day $^{-1}$ for a few weeks prior to and following the summer solstice. During this period, daily solar elevation is great enough for the sun to remain above the Kukri Hills to the south of the LH basin. This contributes incident radiation to the area during the 'evening' hours at HOEM, while BOYM remains topographically shaded.

Additional surface PAR distribution maps were developed on bimonthly intervals for Taylor Valley using the Area T-sPAR model (Fig. 8). The model aggregates total daily surface PAR over the specified time interval and reports the daily average by dividing over the number of days in the interval (14 days for all maps, except for the summer solstice map, which includes 15 days). The complete set of maps for the summer is included as Supplementary Material. Maps were generated using two different scales. The seasonal scale illustrates the progression of surface PAR across Taylor Valley, providing context for the change observed over the summer. The interval scale distinguishes the small
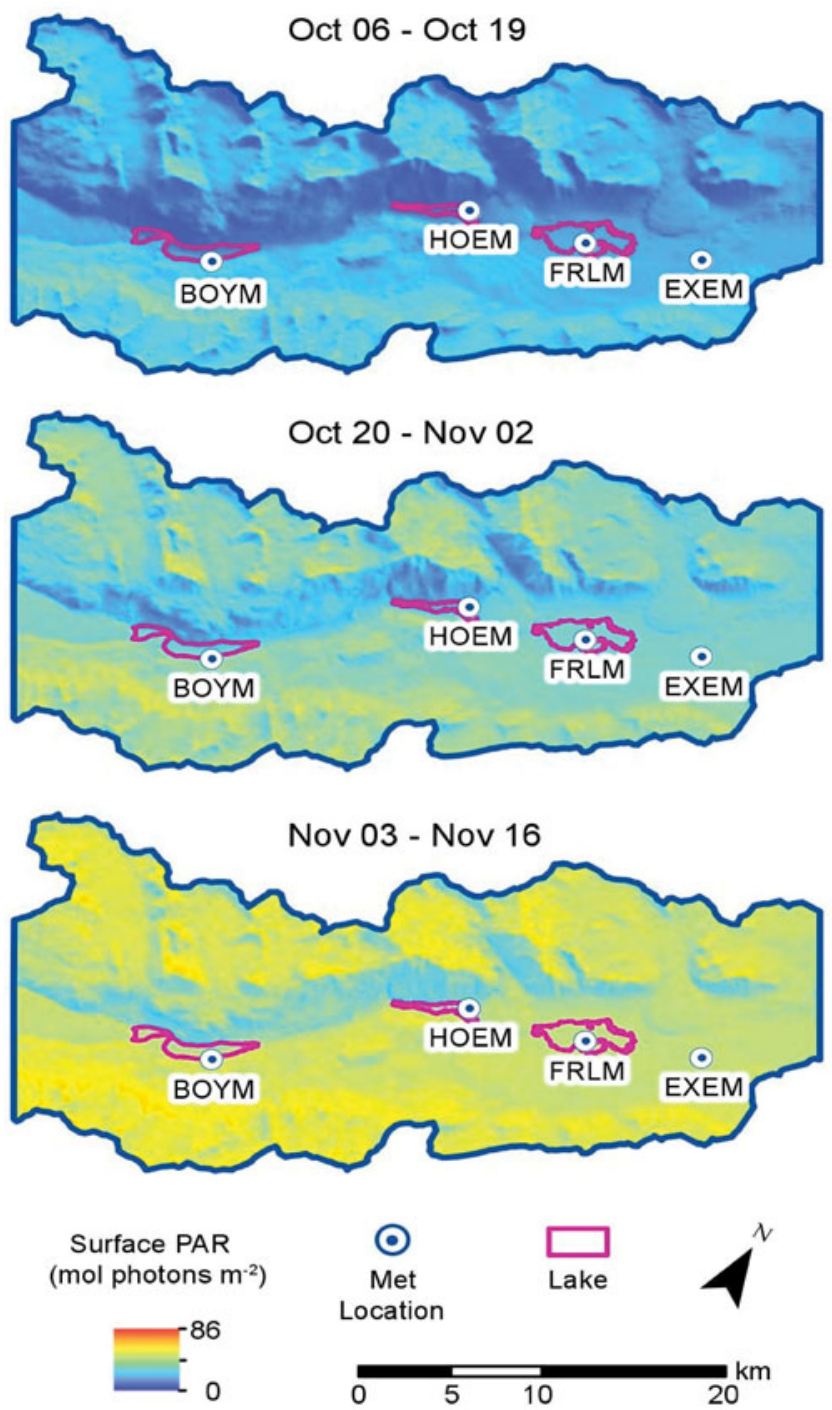

Fig. 8. Bimonthly surface PAR distribution maps covering a 6 week period between 6 October and 16 November. Values are for the timespan's daily average, ending at $23 \mathrm{~h} 59.59$ on the listed date. Maps use the same distance scale. The surface PAR scale is set to the range of values observed over the entire summer.

difference in the range of surface PAR that drives biological processes on the valley floor and within lake waters. These maps can be used by field parties to identify future sampling sites. The shorter timescales of these surface PAR estimates can also be correlated with indices of primary productivity and measurements of underwater PAR.

\section{Application to NPP in Taylor Valley lakes}

One potential use of the T-sPAR toolbox is to improve estimates of NPP in Taylor Valley. Area T-sPAR was used in order to calculate total incident PAR for Taylor 
Table V. Summary statistics for total annual surface PAR estimated by Area T-sPAR.

\begin{tabular}{lccc}
\hline Area & $\begin{array}{c}\text { Range } \\
\left(\text { mol photons } \mathrm{m}^{-2}\right)\end{array}$ & $\begin{array}{c}\text { Total PAR by } \\
\text { surface area } \\
\left(\text { mol photons } \mathrm{m}^{-2}\right)\end{array}$ & $\begin{array}{c}\text { Total PAR } \\
\text { across surface } \\
\text { (giga-mol photons) }\end{array}$ \\
\hline Taylor Valley & $3525-11255$ & 7920 & 5327.02 \\
LF & $7185-7609$ & 7596 & 51.81 \\
LH & $5647-7679$ & 6750 & 15.32 \\
LB & $4741-7724$ & 6903 & 31.28 \\
\hline
\end{tabular}

Valley's lake surfaces and normalized by surface area to allow for comparison (Table V). The effects of annual topographical shading on each lake are evident in Taylor Valley's individual lake maps (Fig. 9). Lake Fryxell, which occupies the widest basin and is surrounded by the lowest ridgeline compared to the other lakes, is the only lake to receive annual values of between 7000 and $8000 \mathrm{~mol}$ photons $\mathrm{m}^{-2}$ across its entire surface, and overall annual surface PAR generally increases from west to east.

Lakes Bonney and Hoare both about the southern slopes of the Asgard Range. As a result, topographical shading bisects the distribution of surface PAR for these two lakes between their northern and southern shores. Annual surface PAR on LB is approximately evenly split, with the northern edge of the lake receiving annual values of between 6000 and $7000 \mathrm{~mol}$ photons $\mathrm{m}^{-2}$, while the southern edge receives annual values of between 7000 and $8000 \mathrm{~mol}$ photons $\mathrm{m}^{-2}$. Most of LH's surface receives annual values of between 6000 and $7000 \mathrm{~mol}$ photons $\mathrm{m}^{-2}$ due to topographical shading from the west. Only the lake's easternmost edge receives annual values

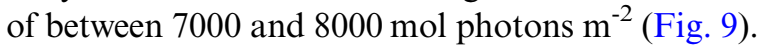

\section{Discussion}

\section{Meteorological record}

A best-fit LOESS curve was derived from the daily PAR flux for each meteorological station and used to calculate the limits of the upper $1 \mathrm{SD}$ confidence interval. The estimated potential maximum daily flux under cloudless conditions was set above the maximum mean value because consistent cloudless conditions during solar noon are a statistical anomaly. Any degree of reduction in transmittivity at this time would result in values that are lower than the absolute maximum potential. The choice of $\mu+1 \sigma$ was based on apparent best fit for all stations without over-predicting observations. The outlying top $16 \%$ of observed maximum values are possible in unique circumstances where high albedo can concentrate diffuse radiation as described by Orgill \& Hollands (1977).
The observed lower frequency of cloud-free days at the more coastal AWS when compared to more inland stations agrees with previous reports of the positive correlation between cloud coverage and proximity to the ocean (Doran et al. 2002). As the CC model relies on the difference between measured and expected PAR, it is difficult to determine conclusively the accuracy of frequency estimates at the beginning and end of the summer (Fig. 3). The low availability of radiation during the fringe months makes the difference between overcast and clear days too small for sensors to discern. In addition, at such low solar angles, the sun may remain unobstructed by cloud coverage or illuminate clouds from beneath. Under these conditions, cloud coverage would contribute to an increase in surface radiation by reflecting incident radiation downwards. Given these considerations, it is recommended to limit conclusions only to estimates between October and March.

\section{Toolbox parameters}

The relative proximity of HOEM and FRLM $(\sim 6.6 \mathrm{~km})$ ensures that cloudless conditions persisted at both locations, while each station was affected differently by topographical shading for the calculation of the diffuse component for each station. The optimal diffusivity parameter derived from T-sPAR was 0.3 , which is higher than the measured values at both HOEM (0.15) and FRLM (0.26). The skylight fraction has an inverse relationship with wavelength (McKay et al. 1994) and therefore an increase in the PAR fraction of total SWR would result in an increase in diffuse contribution as radiation is shifted to lower wavelengths.

The transmittivity parameter that yields the lowest error for Taylor Valley is 0.7. Average transmittivity for all stations was derived as the ratio of SWR exceeding $300 \mathrm{~W} \mathrm{~m}^{-2}$ measured at each AWS (representing bright sun conditions) and solar flux at the top of the atmosphere for the entire data set (Andersen et al. 2015). The transmittivity derived from observations is 0.74 , which is greater than that used in the T-sPAR toolbox. We suggest that this difference is due to differences in the calculation of observed transmittivity versus incident SWR derived from a model. The observed transmittivity represents both diffuse and direct radiation as a fraction of the solar flux at the top of the atmosphere. In the ArcMap toolbox, transmittivity is only applied to the direct component, which is then augmented by the diffuse component in order to derive total incident SWR.

The PAR fraction of SWR used in the toolbox $\left(0.383 \mathrm{~W} \mathrm{~m}^{-2}\right.$ per $1 \mu \mathrm{mol}$ photons $\left.\mathrm{m}^{-2} \mathrm{~s}^{-1}\right)$ is lower than that observed by Clow et al. (1988) at $\mathrm{LH}\left(0.505 \mathrm{~W} \mathrm{~m}^{-2}\right.$ per $1 \mu \mathrm{mol}$ photons $\mathrm{m}^{-2} \mathrm{~s}^{-1}$ ) and by Stefan et al. (1983) in Minnesota $\left(0.488 \mathrm{~W} \mathrm{~m}^{-2}\right.$ per $1 \mu \mathrm{mol}$ photons $\left.\mathrm{m}^{-2} \mathrm{~s}^{-1}\right)$. The fraction 

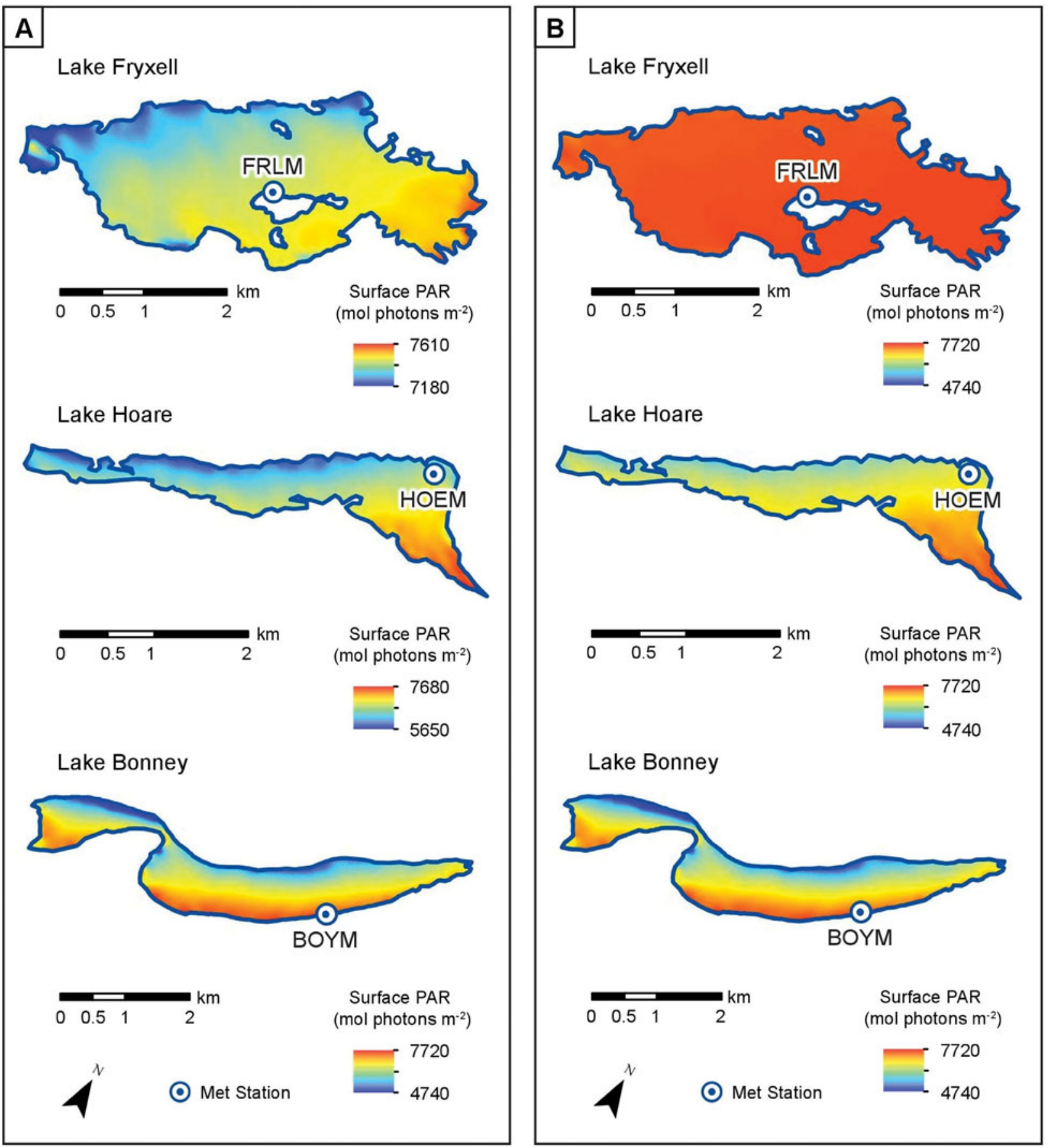

Fig. 9. Total annual surface PAR by lake surface estimated using the Area T-sPAR. Lakeshore boundaries are set to 19 December 2014. Lake maps use various distance scales. a. Surface PAR scale set to range by lake surface. b. Surface PAR scale set to the shared range of all lake surfaces.

of PAR relative to SWR varies by location and time of year. The toolbox uses the average conversion from $\mathrm{W} \mathrm{m}^{-2}$ to $\mathrm{mol}$ photons $\mathrm{m}^{-2}$ day $^{-1}$ between October and March for all stations so that it is optimized during the field season and across the entire valley. During the transition to and from winter, we observe a higher fraction of PAR. Annual-scale variability in the conversion factor is probably attributable to the increased ray path and spectral transmission of the atmosphere. For FRLM, EXEM and BOYM, the lowest PAR fraction occurs near the solstice. HOEM, however, exhibits more asymmetry. It experiences a few brief increases in the conversion factor from approximately March through May and one occurring during the solstice. Daily variability in the conversion factor at HOEM explains the variability in the error. 
Spatial variability in the conversion factor explains the magnitude of error. BOYM has the highest conversion factor and HOEM has the lowest. EXEM and FRLM both fall in the middle. Because the conversion factor used in the toolbox is the average for all stations, EXEM and FRLM are closest to the average and have the lowest error. Because HOEM has the lowest conversion factor of all stations, when the fraction of PAR increases to a value closer to the one used in the toolbox, the error decreases.

\section{Topographical sensitivity}

The trend in error at HOEM stands out from other stations, probably owing to its position nearer to extreme topography. Topography influences both the diffuse fraction as well as the conversion factor. The toolbox overestimates PAR during October and February, when the sun elevation is the same as the elevation of the surrounding topography for the majority of the day. Under optimum diffuse conditions for HOEM (Fig. 5), once the sun is above the surrounding peaks for the majority of the day, the error decreases again to almost zero. BOYM is also affected by sun elevations equal to the surrounding topography, but the sign is the opposite to that of LH. At BOYM, the toolbox actually underestimates PAR. We suggest that the difference between BOYM and HOEM is due to the position of HOEM being nearer to the steep north wall of Taylor Valley, resulting in a lower diffuse fraction. BOYM is located on the south side of the lake in a comparatively wider portion of Taylor Valley, which could allow for a higher fraction of diffuse light.

\section{The T-sPAR toolbox}

The T-sPAR toolbox automates the process of creating point and area PAR estimates. The toolbox uses the parameters described in this study as defaults in order to calculate surface PAR in Taylor Valley's basin and applies necessary scaling coefficients via Raster Math in order to generate daily totals of surface PAR. User-defined input is limited to the date or timeframe of interest. Cloud cover is factor calculated from the $\mathrm{CC}$ model and scales results based on meteorological observations.

The Point T-sPAR toolbox model requires latitude/ longitude coordinates for point(s) of interest in decimal degrees. Values are input using a simple template table in order to project the points onto the DEM. The model provides estimates for clear conditions by default, but can incorporate $\mathrm{CC}$ as needed. When results are constrained by atmospheric conditions, multipoint calculations should ideally be limited to locations within the same lake basin. Point T-sPAR only accepts a single

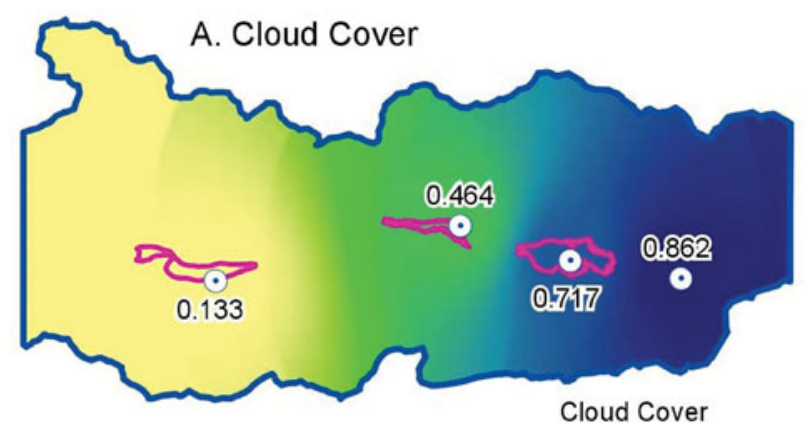

(1) Overcast

(0) Clear
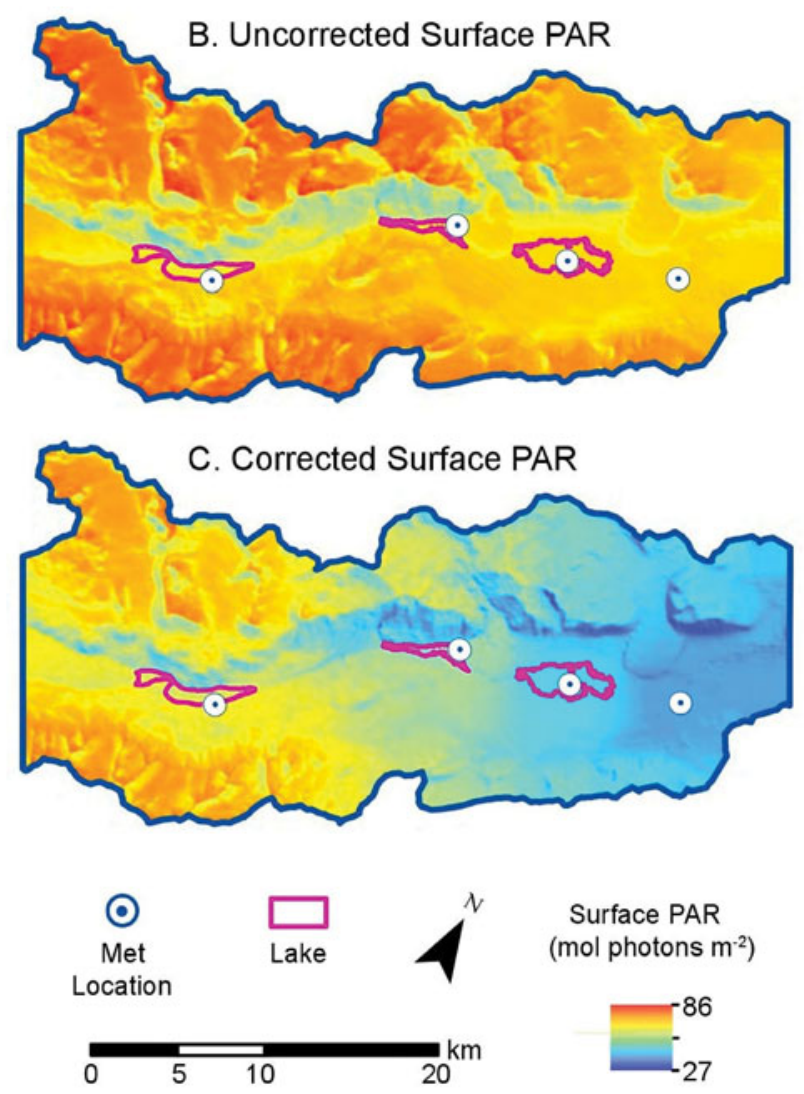

Fig. 10. Surface PAR map with an interpolated CC correction for a hypothetical 19 December created with the Area T-sPAR toolbox. a. Cloud cover raster mask shows interpolated atmospheric conditions based on input values for each meteorological station. Overcast conditions dominate on the eastern end of the valley, while clear conditions prevail in the west. b. Estimated surface PAR without CC correction. Values range between 39 and 86 mol photons $\mathrm{m}^{-2}$ day $^{-1}$. c. Estimated surface PAR corrected with CC mask. The new raster shows the impact of $\mathrm{CC}$ on the eastern side of the valley with only a slight reduction on the western end. Values range between 27 and 80 mol photons $\mathrm{m}^{-2}$ day $^{-1}$.

value for the $\mathrm{CC}$ factor and applies it uniformly to all points in the table. Coordinates in various lake basins 
should be calculated separately using the CC factor for the nearest station. The model interprets each point's spatial relationship and calculates surface PAR for its coordinates, outputting a table of results that can be further manipulated outside of ArcMap.

The Area T-sPAR toolbox generates PAR raster maps for all of Taylor Valley and each of the major lakes. This model requires the input of $\mathrm{CC}$ factors for all four meteorological stations. The spatial relationship of CC factors is interpolated across the entire valley using IDW to create a CC mask (Fig. 10a). The IDW interpolation creates a sphere of influence around each of the four sample points that decreases with distance when other sample points are present within the sphere. The result is a smooth gradient transition from point to point.

Surface PAR is then estimated based on 'cloudless' conditions (Fig. 10b) and merged with the CC mask using raster multiplication in order to create a CC-corrected map (Fig. 10c). Final PAR values are scaled down based on the magnitude of the $\mathrm{CC}$ values to a maximum of $50 \%$ of the pixel's 'cloudless' potential. Corrected maps are clipped using 19 December 2014 lakeshore boundaries in order to produce surface PAR maps by lake, and solargraphic contour lines with intervals of $1 \mathrm{~mol}$ photon $\mathrm{m}^{-2}$ are drawn in order to help distinguish surface values.

\section{Conclusions}

The best-fit LOESS curve of maximum daily PAR flux is representative of the nearly 20 year daily average; however, interannual variability of incident radiation due to changing atmospheric and solar conditions could lead to over- or under-estimates of the mean daily PAR flux near the solstice. EXEM has the highest frequency of overcast days, while BOYM has the lowest, which suggests a positive correlation between proximity to the coast and total days with high CC. The BOYM, EXEM and FRLM meteorological stations observe increasingly overcast conditions towards the end of the summer, peaking during the month of February. HOEM, on the other hand, records the highest frequency of overcast conditions during the month of December. Incorporating a temporal component improves estimates of CC in Taylor Valley.

Diffuse and reflected radiation accounts for $15-26 \%$ of global radiation, consistent with fractions reported at other latitudes. ArcMap's Point Solar Radiation and Area Solar Radiation tools are efficient methods for predicting surface PAR in the MDVs where spatial and temporal constraints limit extensive empirical measurements. Values of $\mathrm{D}=0.3$ and $\mathrm{T}=0.7$ had the lowest root mean standard deviation (between 1.6 and 3.6 daily mol photons $\mathrm{m}^{-2}$ ) of all models tested. Using these parameters, Point T-sPAR predicts EXEM to have the highest total daily PAR around the summer solstice, which is in agreement with meteorological observations; however, it fails to predict FRLM as the location with the second highest amount of total daily PAR, favouring BOYM instead. ArcMap characteristically under-predicts the radiation envelope during the weeks leading up to and following the summer solstice. Further research into using TRMs at high latitudes and low solar angles would greatly improve this model. In addition, incorporation of a conversion factor model dependent on the geometry of topography and sun position would also improve the model.

Presently, T-sPAR is sufficient at predicting surface radiation with enough accuracy to improve models for NPP in Taylor Valley. Bimonthly surface PAR maps identify total aggregate values on timescales that inform the choice of future sampling sites in the field and constrain the NPP of Taylor Valley's ice-covered lakes. Minimal user input and a simple graphical interface facilitate estimating surface PAR for any day of the Antarctic summer. The T-sPAR toolboxes allows users to calculate single-point approximations and correct estimated 'cloudless' surface values with modelled $\mathrm{CC}$ observations.

T-sPAR uses a higher-resolution DEM than previous radiation models in Taylor Valley and highlights the heterogeneous nature of incident PAR within the valley. Biological sampling is limited to a few locations each year due to logistical constraints. T-sPAR outputs show that on lake surfaces annual radiation varies by as much as $1500 \mathrm{~mol}$ photons $\mathrm{m}^{-2}$ within only a few hundred metres along the steepest PAR gradient. Increased resolution of incident radiation informs biological sampling locations that are better representative of the whole, especially where ecosystems are so sensitive to small perturbations in light availability. The T-sPAR toolboxes help constrain the NPP within Taylor Valley's ice-covered lakes, as well as improve the understanding of PAR in one of the Earth's more extreme ecosystems.

\section{Acknowledgements}

The authors thank Andrew Dombard, Max Berkelhammer and Chris McKay for their suggested edits.

\section{Author contributions}

DA is responsible for the development of the GIS toolbox and cloud cover model. He is also responsible for the field surveys and for maintaining the long-term automated weather stations. He contributed to the concept and design of the project. PTD contributed to the concept and design of the project, provided field assistance and edited the manuscript prior to submission. MM provided supported for the development of the toolbox, tested toolbox accuracy and edited the manuscript for submission. 


\section{Financial support}

DA received generous support from Mexico's Consejo Nacional de Ciencia y Tecnología (CONACYT), the University of Illinois at Chicago's Department of Earth and Environmental Science and Louisiana State University's Department of Geology and Geophysics. This work was funded by the National Science Foundation LTER grant 1637708.

\section{Supplemental material}

Thirty-four supplemental maps will be found at https:// doi.org/10.1017/S0954102020000218.

\section{References}

Andersen, D.T., McKay, C.P. \& Lagun, V. 2015. Climate conditions at perennially ice-covered Lake Untersee, East Antarctica. Journal of Applied Meteorology and Climatology, 54, 1393-1412.

Bromley, A.M. 1986. Precipitation in the Wright Valley. New Zealand Antarctic Record, 6, 60-68.

Chinn, T.J. 1993. Physical hydrology of the dry valley lakes. Antarctic Research Series, 59, 1-51.

Cleveland, W.S. \& Devlin, S.J. 1988. Locally weighted regression: an approach to regression analysis by local fitting. Journal of the American Statistical Association, 83, 10.2307/2289282.

Clow, G.D., McKay, C.P., Simmons JR, G.M. \& Wharton JR, R.A. 1988. Climatological observations and predicted sublimation rates at Lake Hoare, Antarctica. Journal of Climate, 1, 715-728.

Csatho, B., Schenk, T., Krabill, B., Wilson, T., Lyons, W.B., McKenzie, G., et al. 2005. Airborne laser scanning for high-resolution mapping of Antarctica. Eos, 86, 237-238.

Dana, G.L., Wharton, R.A.J. \& Dubayah, R. 1998. Solar radiation in the McMurdo Dry Valleys, Antarctica. Antarctic Research Series, 72, $39-65$.

Dana, G.L., Wharton, R.A.J. \& Fountain, A.G. 1996. McMurdo Dry Valleys LTER: solar radiation on glaciers in Taylor Valley, Antartica. Antarctic Journal, 31, 191-193.

Dhaulakhand, A.B., Joshi, R.P. \& Joshi, M.C. 1993. Availability of photosynthetically active radiation in Antarctica. Current Science, 65, 703-705.

Doran, P.T., McKay, C.P., Clow, G.D., Dana, G.L., Fountain, A.G., NyLEN, T.H., et al. 2002. Valley floor climate observations from the McMurdo Dry Valleys, Antarctica, 1986-2000. Journal of Geophysical Research, 107, 10.1029/2001JD002045.

Doran, P.T., McKay, C.P., Fountain, A.G., Nylen, T.H., McKnight, D.M., JAROS, C., et al. 2008. Hydrologic response to extreme warm and cold summers in the McMurdo Dry Valleys, East Antarctica. Antarctic Science, 20, 10.1017/S0954102008001272.
Dubayah, R. \& Rich, P.M. 1995. Topographic solar radiation models for GIS. International Journal of Geographical Information Systems, 9, 10.1080/02693799508902046.

ESRI 2015. How solar radiation is calculated. ArcGIS 10.3.1 help. Available at http://desktop.arcgis.com/en/arcmap/10.3/tools/spatialanalyst-toolbox/how-solar-radiation-is-calculated.htm.

Fountain, A.G., Nylen, T.H., Monaghan, A., Besagic, H. \& Bromwich, D.H. 2010. Snow in the McMurdo Dry Valleys, Antarctica. International Journal of Climatology, 30, 633-642.

Fountain, A.G., Lyons, W.B., Burkins, M.B., Dana, G.L., Doran, P.T., LewIS, K.J., et al. 1999. Physical controls on the Taylor Valley ecosystem, Antartica. BioScience, 49, 961-971.

Fu, P. \& Rich, P.M. 2000. The Solar Analyst 1.0 user manual. Hetrick, WA: Helios Environmental Modeling Institute, 1616 pp.

Hawes, I., Giles, H. \& Doran, P.T. 2014. Estimating photosynthetic activity in microbial mats in an ice-covered Antarctic lake using automated oxygen microelectrode profiling and variable chlorophyll fluorescence. 59, 10.4319/1o.2014.59.3.0674.

Lacelle, D., Lapalme, C., Davila, A.F., Pollard, W., Marinova, M., Heldmann, J., et al. 2016. Solar radiation and air and ground temperature relations in the cold and hyper-arid Quartermain Mountains, McMurdo Dry Valleys of Antarctica. Permafrost and Periglacial Processes, 27, 10.1002/ppp.1859.

LeVY, J. 2013. How big are the McMurdo Dry Valleys? Estimating ice-free area using Landsat image data. Antarctic Science, 25, 10.1017/ S0954102012000727.

Long, M.H., Rheuban, J.E., Berg, P. \& Zieman, J.C. 2012. A comparison and correction of light intensity loggers to photosynthetically active radiation sensors. Limnology and Oceanography: Methods, 10, 416-424.

McCree, K.J. 1981. Photosynthetically active radiation. In Lange, O.L., Nobel, P.S., Osmond, C.B. \& Ziegler, H., eds. Physiological plant ecology, Vol. 12. Berlin: Springer, 41-55.

McKay, C.P., Clow, G.D., Andersen, D.T. \& Wharton JR, R.A. 1994. Light transmission and reflection in perennially ice-covered Lake Hoare, Antarctica. Journal of Geophysical Research: Oceans, 99, 10.1029/94JC01414.

Mizoguchi, Y., Yasuda, Y., Ohtani, Y., Watanabe, T., Kominami, Y. \& YAMANoI, K. 2013. A practical model to estimate photosynthetically active radiation using general meteorological elements in a temperate humid area and comparison among models. Theoretical and Applied Climatology, 115, 10.1007/s00704-013-0912-2.

ObrYк, M.K., Doran, P.T. \& Priscu, J.C. 2014. The permanent ice cover of Lake Bonney, Antarctica: the influence of thickness and sediment distribution on photosynthetically available radiation and chlorophyll- $a$ distribution in the underlying water column. Journal of Geophysical Research: Biogeosciences, 119, 10.1002/2013JG002433.

Orgill, J.F. \& Hollands, K.G.T. 1977. Correlation equation for hourly diffuse radiation on a horizontal surface. Solar Energy, 19, 10.1016/ 0038-092X(77)90006-8.

Stefan, H.G., Cardoni, J.J., Schiebe, F.R. \& Cooper, C.M. 1983. Model of light penetration in a turbid lake. Water Resources Research, 19, 109-120. 